Available online at GSC Online Press Directory

GSC Biological and Pharmaceutical Sciences

e-ISSN: 2581-3250, CODEN (USA): GBPSC2

Journal homepage: https://www.gsconlinepress.com/journals/gscbps

(RESEARCH ARTICLE)

\title{
Evaluation of the hemogram of Oryctolagus cuniculus envenomus
}

\author{
Obou Constantin Okou 1, 4. ${ }^{*}$ N'guessan Emmanuel Assemian 2, Kouadio Bernard Allali ${ }^{3}$, Guy Childeric Bingo \\ 1 and Allico Joseph Djaman 4 \\ 1 Department of Biochemistry and Microbiology, Agroforestry Training and Research Unit, Jean Lorougnon Guédé \\ University, Côte d'Ivoire. \\ 2 Department of Biology and Tropical Ecology, Environmental Training and Research Unit, Jean Lorougnon Guédé \\ University, Côte d'Ivoire. \\ ${ }^{3}$ Environment and Health Department, Entomology and Herpetology Unit, Pasteur Institute of Côte d'Ivoire. \\ ${ }^{4}$ Department of Biology-Health, Biosciences Training and Research Unit, Félix Houphouët-Boigny University Abidjan, \\ Côte d'Ivoire.
}

Publication history: Received on 15 November 2020; revised on 25 November 2020; accepted on 27 November 2020

Article DOI: https://doi.org/10.30574/gscbps.2020.13.2.0384

\begin{abstract}
The overall objective of this study was to evaluate the hemolysing action of Naja nigricollis venom on rabbit blood. To carry out this study, three batches of three rabbits were formed with two control batches and one experimental batch. Each control lot is composed of three rabbits (males or females) while the experimental lot is composed of two males and one female. Each rabbit from the control lots was separately collected in the purple tube (EDTA) and transported to the laboratory for analysis. The rabbits from the experimental batch were also collected distinctly a few minutes after the injection of the venom of Naja nigricollis for the analysis of haematological parameters. However, before the analysis of the hematological parameters of the rabbits from the control and experimental batches, an in vitro hemolysis test of Naja nigricollis venom was performed to verify its hemolysing power. The results showed that Naja nigricollis venom has a dose-dependent in vitro hemolysing power. As for the haemogram, it revealed that the venom of Naja nigricollis has a decreasing effect on blood cells (red and white blood cells), on haemoglobin and on haematocrit, and an elevation on MGVs thus promoting anaemia.
\end{abstract}

Keywords: Venom; Naja nigricollis; Haemogram

\section{Introduction}

Envenimation is the introduction into the body of a toxic substance, venom, due to the bite of a snake, the sting of a scorpion, a wasp, etc. The most dangerous is that caused by snake bites [1], [12]. Indeed, venom contains a complex mixture of enzymes, peptides and proteins of low relative molecular weight, with specific chemical and biological activities, which can lead to death from neurological and/or hematological disorders [9], [12]. This case of envenimation is a problem affecting the five continents of the world. Globally, the annual incidence of snake bites exceeds six million [2], [7], [6]. However, Africa records more than one million bites causing 600,000 cases of envenomation. Also in Africa, nearly 250,000 patients are treated, nevertheless, there are more than 20,000 deaths [4], [5].

In Africa, generally speaking, the venomous snakes responsible for all these disasters are mainly Viperidae and Elapidae. Viperidae (vipers) are the most widespread venomous species and do the majority of damage while Elapidae are the

\footnotetext{
${ }^{*}$ Corresponding author: Obou Constantin Okou

Department of Biochemistry and Microbiology, Agroforestry Training and Research Unit, Jean Lorougnon Guédé University, Côte d'Ivoire.
}

Copyright (c) 2020 Author(s) retain the copyright of this article. This article is published under the terms of the Creative Commons Attribution Liscense 4.0. 
most dangerous snakes because of the high toxicity of their venom [14]. It is classic to oppose cobraic poisoning, essentially neurotoxic, and viperine poisoning, dominated by necrosis and hemorrhagic syndromes. In practice, this distinction must be qualified [5]. In fact, the diversity of substances, contained in the venoms of the species of these two families of snakes, vary according to the species and even between individuals of the same species, which makes certain species exceptional by the action of their venom. Among these exceptions is the venom of Naja nigricollis, one of the most dangerous and representative species of Elapidae in Africa. Its venom contains cytoxins that target certain blood cells and those of certain organs such as the heart. Its action on these organs creates dysfunctions whose effects associated with those of these neurotoxins could have a serious impact on the breathing of the victim and lead to his death [11], [3].

In fact, the haematological parameters or haemogram are made up of blood figurative elements (blood cells) divided into red lineage cells (red blood cells, reticulocytes), white lineage cells (lymphocytes, granulocytes, monocytes) and platelets. Under physiological conditions, the proportion of each cell type is within a range determined for each species. The absolute or relative amount of the different cell types may vary following exposure to a toxicant or under pathological conditions [10]. According to the same author, hematological toxicity is expressed by an increase or decrease in the number of peripheral blood cells of one or more cell lines. These cytopenias have various consequences: anemic syndrome, hemorrhagic, infectious by immunosuppression, etc.... The origin of this change in the blood count may be central by spinal cord injury or peripheral by immune destruction or not. The objective of this study was to evaluate the haemogram of a rabbit that had become envenomized.

\section{Material and methods}

\subsection{Animal material}

For this study, nine rabbits including five males and four females of Hyplus breed, aged two and a half months were purchased from a breeder in the locality of Daloa (Côte d'Ivoire). After the acclimatization period the weight of the rabbits varied between 1.45 and $2.4 \mathrm{~kg}$. Beside this animal model, the venom of Naja nigricollis (spitting cobra) was also used and supplied by the Pasteur Institute of Adiopodoumé (Côte d'Ivoire).

\subsection{In vitro hemolysis test method}

Two control lots (lot 1 and lot 2) were established for this test. Lot 1 consists of three males and lot 2 consists of three females. Among these control lots, a blood sample was taken from one of them in order to perform the in vitro hemolysis test of Naja nigricollis venom. To perform this test, 10 tubes were used, including a control tube and 9 experimental tubes. The stock solution was prepared in tube 1 by dissolving $1.6 \mathrm{mg}$ of venom crystals in $1 \mathrm{~mL}$ of physiological water. In the remaining 9 tubes (tubes 2 to 10) a volume of $0.5 \mathrm{~mL}$ of physiological water was added. The venom concentration ranges were prepared using the double dilution technique of geometric ratio $1 / 2$. It consisted in taking $0.5 \mathrm{~mL}$ of the stock solution (tube 1) and transferring it to $0.5 \mathrm{~mL}$ of physiological water from tube 2 and homogenizing it. This procedure was repeated up to tube 9 . From tube 9 , a volume of $0.5 \mathrm{~mL}$ was collected and subsequently discarded. Thus, concentrations in the tubes ranged from $1.6 \mathrm{mg} / \mathrm{mL}$ to $6.26 .10-3 \mathrm{mg} / \mathrm{mL}$. To these 9 experimental tubes and to the control tube (tube 10), 5 drops of rabbit whole blood was added and homogenized manually. After homogenization, all preparations were incubated at room temperature for 30 to 40 minutes for microscopic observation. This observation was carried out at magnification 40 (X40). For this purpose, the preparations in tubes 1 (SS); $2 ; 3$ and tube 10 (control tube) were diluted distinctly to $1 / 5$ th. Then each dilution was spread between slide and slide by putting the dilution of tube 10 (control) and an experimental dilution (e.g. tube 1). This last operation was also performed for tube 2 and tube 3.

\subsection{Method of blood collection}

In general, blood samples were taken from the short saphenous vein and/or the femoral vein. The restraint method was performed by three people. The areas where these veins were located were previously exposed with a pair of scissors. The vacutainers into which the needles were inserted allowed the sampling to be carried out using the purple tubes (EDTA). The resulting tubes were stored in a cooler containing ice and then transported to the laboratory for analysis.

\subsection{Method of carrying out experimental tests}

For the experimental tests, a quantity of $2 \mathrm{mg}$ of venom crystals was dissolved in $0.5 \mathrm{~mL}$ of physiological water in order to have a concentration of $4 \mathrm{mg} / \mathrm{mL}$. This is the concentration that was injected into the rabbits. Indeed, according to [8], the median lethal dose for a $2 \mathrm{~kg}$ rabbit is $2 \mathrm{mg} / \mathrm{kg}$ body weight in intramuscular injection. 


\section{Results}

\subsection{Result of the hemolysing power of venom in vitro}

Figures 1 ( $a$ and $b$ ); 2 ( $a$ and $b$ ) and 3 ( $a$ and $b$ ) are the results of the effects of different concentrations of the venom tested in vitro on red blood cells. These figures show that, in general, the density of red blood cells varies compared to the control depending on the concentrations tested. However, this density is higher when the concentration is low $(0.4$ $\mathrm{mg} / \mathrm{mL})$ and low when the concentration is high $(1.6 \mathrm{mg} / \mathrm{mL})$.
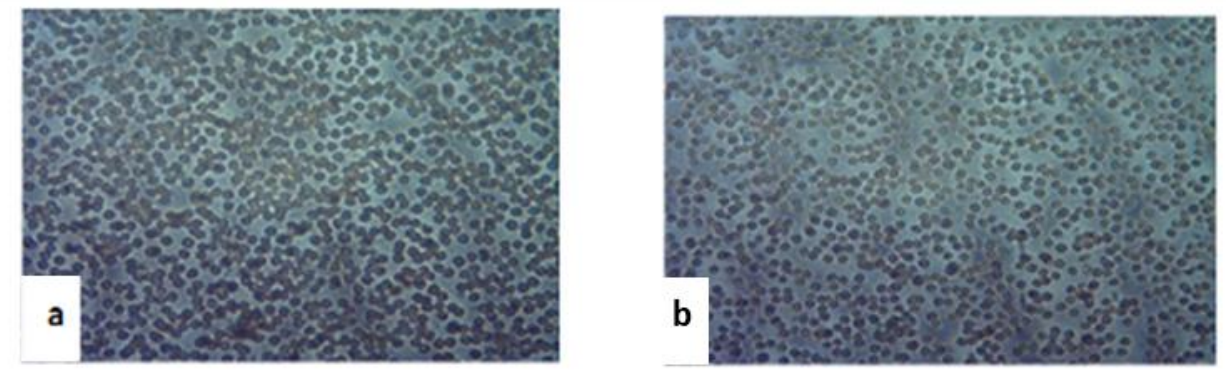

Figure 1 Hemolysing power of venom on red blood cells (at 40 magnification) 1.a: control red blood cells; $1 . b$ : red blood cells at a concentration of $0.4 \mathrm{mg} / \mathrm{mL}$ venom
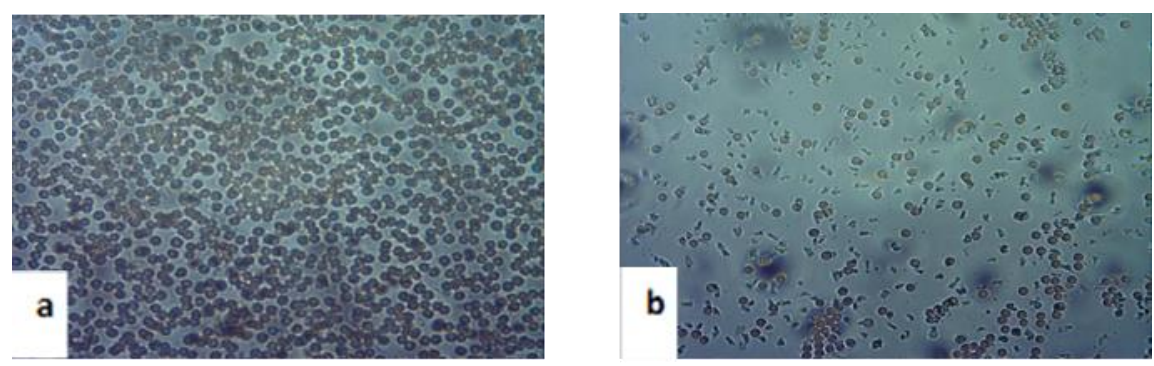

Figure 2 Hemolysing power of venom on red blood cells (at 40 magnification) 2.a: control red blood cells; 2.b: red blood cells at a concentration of $0.8 \mathrm{mg} / \mathrm{mL}$ venom
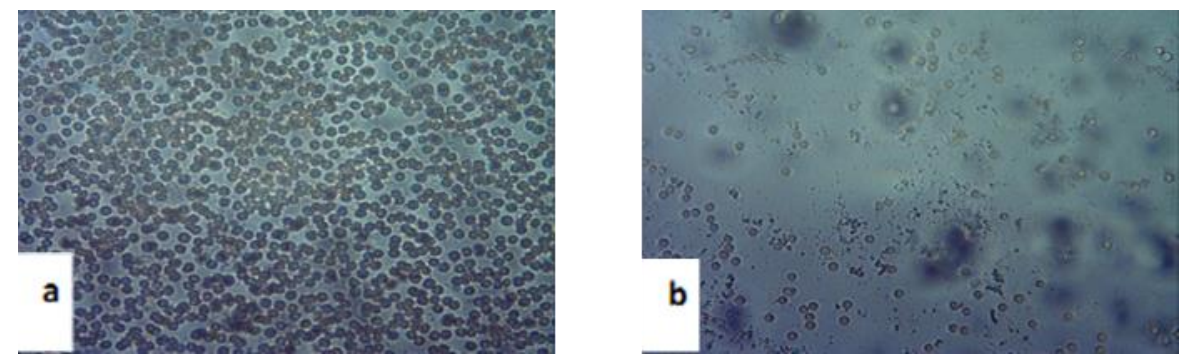

Figure 3 Hemolysing power of venom on red blood cells (at magnification 40) 3.a: control red blood cells; 3.b: red blood cells at a concentration of $1.6 \mathrm{mg} / \mathrm{mL}$ venom 
Table 1 Hematological parameters of untreated control and poisoned rabbit lots.

\begin{tabular}{|c|c|c|c|c|c|c|c|c|c|c|c|c|c|c|c|}
\hline & \multicolumn{6}{|c|}{ Lot 1: Males controls } & \multicolumn{6}{|c|}{ Lot 2: Females controls } & \multicolumn{3}{|c|}{ Lot 3: Envenomed } \\
\hline & M7 & M10 & M16 & Ave & $\mathrm{Sd}$ & Reference values & $\mathrm{F} 1$ & F10 & F12 & AVE & $\mathrm{Sd}$ & Reference values & M18 & M19 & $\mathrm{F} 4$ \\
\hline Weight & 1.9 & 2.4 & 1.5 & 1.91667 & 0.475 & $1.442-2.392$ & 1.7 & 2 & 2 & 1.9 & 0.173 & $1.73-2.07$ & 1.9 & 1.9 & 1.9 \\
\hline WBC & 11 & 11 & 11 & 10.7667 & 0.462 & $10.30-11.23$ & 7 & 5.2 & 5.4 & 5.86667 & 0.987 & $4.88-6.85$ & 6.1 & 4.2 & 6.8 \\
\hline $\mathbf{R B C}$ & 5.7 & 6 & 6.7 & 6.11667 & 0.499 & $5.62-6.62$ & 6.1 & 5.9 & 5.9 & 5.98333 & 0.119 & $5.86-6.10$ & 5.5 & 5.3 & 4.6 \\
\hline Hg & 11 & 12 & 12 & 11.7333 & 0.416 & $11.32-12.15$ & 11 & 11 & 5.9 & 9.37667 & 2.987 & $6.39-12.36$ & 10 & 9 & 11 \\
\hline Ht & 35 & 37 & 40 & 36.9667 & 2.335 & $34.63-39.30$ & 37 & 36 & 38 & 37.0667 & 1.002 & $36.06-38.07$ & 35 & 32 & 36.6 \\
\hline GMV & 62 & 61 & 59 & 60.5667 & 1.069 & $59.50-61.64$ & 62 & 64 & 64 & 63.3333 & 1.422 & 61.91-64.76 & 65 & 64 & 67 \\
\hline МСHC & 20 & 19 & 18 & 19.2 & 0.854 & $18.35-20.05$ & 19 & 19 & 19 & 18.9667 & 0.351 & 18.62-19.32 & 20 & 19 & 21 \\
\hline MCH & 33 & 32 & 31 & 31.7 & 0.9 & $30.8-32.6$ & 30 & 29 & 30 & 29.7333 & 0.635 & $29.10-30.37$ & 31 & 31 & 30 \\
\hline $\mathbf{P t}$ & 769 & 590 & 400 & 586.33 & 184.5 & $401.83-770.83$ & 264 & 270 & 277 & 270.333 & 6.506 & $263.83-276.84$ & 694 & 441 & 331 \\
\hline LC\% & 45 & 50 & 58 & 51.1 & 6.514 & $44.59-57.61$ & 36 & 35 & 36 & 35.8 & 0.608 & $35.19-36.41$ & 45 & 49 & 53 \\
\hline
\end{tabular}

$\mathrm{RBC}=$ Red Blood Cells (x 106/mm3); WBC = White Blood Cells (x 103/mm3); Hg = Hémoglobine (g/dL) ; Ht = Hématocrite (\%) ; MGV = Mean Global Volume ( $\mu 3) ;$ MCHC = Mean Corpuscular Hemoglobin Content (pg/L); $\mathrm{MCH}=$ Corpuscular (or Globular) Mean Hemoglobin Concentration (\%);Pt = Platelets (x103/mm3); LCva = Lymphocytes en valeur absolue $(\%) ; \mathrm{M}=\mathrm{Male} ; \mathrm{F}=$ female ; Ave = Average ; Sd = Standard deviation; Light gray: Low value; Dark gray and bold: High value 


\subsection{Hemogram results of untreated control and envenomed rabbits}

The results of the control rabbits' hemogram (lot 1 and lot 2) indicate that the reference value:

- $\quad$ WBC is between 10.30 and $11.23 \times 103 / \mathrm{mm} 3$ for males and between 4.88 and $6.85 \times 103 / \mathrm{mm} 3$ for females;

- $\quad \mathrm{RBC}$ is included in the range of 5.62 to $6.62 \times 106 / \mathrm{mm} 3$ for males and 5.86 to $6.10 \times 106 / \mathrm{mm} 3$ for females;

- $\quad \mathrm{Hg}$ is 11.32 and $12.15 \mathrm{~g} / \mathrm{dL}$ for males and 6.39 and $12.36 \mathrm{~g} / \mathrm{dL}$ for females;

- Ht is from 34.63 to $39.30 \%$, and 36.06 to $38.07 \%$ for males and females respectively;

- of GMVs is situated between 59.50-61.64 $\mu 3$ and 61.91-64.76 $\mu 3$ for males and females respectively;

- $\quad$ MCHC is comprised between 18.35-20.05 pg/L for males and 18.62-19.32 pg/L for females;

- $\quad \mathrm{MCH}$ is within the range of 30.8-32.6 \% and 29.10-30.37 \% for males and females, respectively;

- $\quad$ Pt is included between $401.83-770.83 \times 103 / \mathrm{mm} 3$ for males and 263.83-276.84 x 103/mm3 for females;

- $\quad$ LC \% is 44.59 and $57.61 \%$, and 35.19 and $36.41 \%$ for males and females, respectively.

The blood counts of the envenomed and untreated rabbits of lot 3 were observed in comparison with the reference values of each parameter studied according to sex:

- The death of all individuals in Lot 3.

- At the level of the males:

- a reduced WBC value in both males,

- a low RBC value of both males,

- a low Hg value for both males,

- a decrease in Ht in a single male,

- a GMV increase in both males.

- $\quad$ At the female level:

- a reduction in $\mathrm{RBC}$,

- $\quad$ an increase in GMVs, MCHCs, Pt and LCs \% in female

\section{Discussion}

\subsection{Result of the hemolysing power of venom in vitro}

The results of the in vitro hemolysis test showed that, in general, the venom of Naja nigricollis has a hemolysing effect on rabbit whole blood. However, these effects are dependent on its concentration. Indeed, hemolysis is more important when the concentration is high. This explains why the density is low with the concentration of $1.6 \mathrm{mg} / \mathrm{mL}$; whereas it is higher with the lowest concentration used $(0.4 \mathrm{mg} / \mathrm{mL})$. This gradual venom action would imply that this effect would be a function of the quantity injected. Therefore, the venom has a dose-dependent action on red blood cells in vitro. These results are consistent with those of [5]. In effect, this author indicates that the effect of Elapidae venom is proportional to the quantity of toxin molecules introduced into the organism.

\subsection{Blood count results of untreated control and poisoned rabbits}

The results of this study reveal that with the exception of the reference values of WBC and Pt which are elevated in males and females, the other reference values are in approximately the same ranges. In addition, the set of hematological baseline values obtained in this study is generally consistent with those of [16], with the exception of the GMV values for males which are below and the MCHCs which are above those of the same author.

If the blood counts of the envenomed and untreated rabbits of lot 3 show a general decrease in blood cells (WBC and RBC) in both males and females, this would suggest that the venom of Naja nigricollis has a cytotoxic action on these blood cells. In fact, the work of [13], [15] have demonstrated the cytotoxic action of this venom. [8] also evoked the destructive action of snake venom on red blood cells which would be at the origin of anaemia. This anemia could be the cause of all the animals in lot 3. According to [16], a deficiency in vitamin D could lead to changes in blood cells. The same author says that the more vitamin D deficiency is marked, the lower the hemoglobin level (anemia) and is due to a deficiency in iron metabolism and a very high number of platelets. This assertion would certainly explain the decrease in hemoglobin in both males and an increase in platelets in the female. The author also states that high platelet levels can lead to cardiovascular disorders. Just as a lack of vitamin D can also affect white blood cells (cells of the immune system that protect against external aggressions). The latter could be the cause of the drop in white blood cells in the two males of lot 3. Consequently, the action of the venom causes a blood disorder because it decreases in most cases the red blood cells in the two males and the female envenomed, lowers the hemoglobin of the two males and the hematocrit of one male, and increases the GMVs of the two males and the female envenomed. [12] Suggests that this disorder may 
be due to the presence of a large quantity of active toxins on the cell membranes. Cytotoxins have many properties that have led to their being given various names: cardiotoxin, direct lytic factor, membrane toxin, hemolysin, cytolysin and cytotoxin (a name that has finally stuck with them). The main property of cytotoxins is to cause lysis of cell membranes Status D: Death

\section{Conclusion}

Ultimately, the venom of Naja nigricollis at a certain dose has a dose-dependent hemolysing power whether in vitro and/or in vivo. The cytotoxins of this venom are responsible for this damage to blood cells. They have decreased red and white blood cells (blood cells), Hg and Ht. However, GMVs have increased. This damage to the hematological parameters would cause anemia.

\section{Compliance with ethical standards}

\section{Acknowledgments}

This article is excerpted from a Master's degree written by Guy Childeric Bingo and defended at the University Jean Lorougnon Guédé of Daloa (Côte d'Ivoire

\section{Disclosure of conflict of interest}

The author declared that no conflict interest.

\section{Statement of ethical approval}

In our country, the declaration of ethical approval is made on humans and not on animals.

\section{References}

[1] Anonymous. Envenimations in the Medical Encyclopedia of Africa. Larousse, Africa 4 Belgium. 1986 ; $1111-15$.

[2] Arfaoui A, Hmimou R, Ouammi L, Soulaymani A, Mokhtari A, Chafiq F, Soulaymani-Bencheick R. Epidemiological profile of snakebites in Morocco. Journal of Venomous Animals and Toxins Including Tropical Diseases. 2009; 15(4): 653-66.

[3] Chippaux JP. Snake bites in intertropical Africa. Health book. 1992; 2: 221-34.

[4] Chippaux JP. Snake bites: appraisal of the global situation. Bulletin of World Heath Organisation. 1998; 76(5): 515-24.

[5] Chippaux JP. The snakes of West and Central Africa. Tropical Fauna and Flora Collection. 2006; 35: 11-329.

[6] Coulibaly SK, Hami H, Hmimou R, Mokhtari A, Soulaymani R, Maiga A, Soulaymani A. Ophidian poisoning in the Koulikoro region of Mali. Antropo. 2013; 29: 41-7.

[7] El Koraichi A, Tsala G, El Haddoury M, Ech-chérif El Kettani S. Epidemiology of viper bite poisoning in the pediatric intensive care unit at the Rabat Children's Hospital in Morocco. French Annals of Anaesthesia and Resuscitation. $2011 ; 30(1): 83-5$.

[8] Fumba G. Anti-venomous medicinal plants from Burundi. The presses of the future, Arlon (Belgium). $1983 ; 136$.

[9] Gentilini M. Poisonous animals, Flammarion medicine science. $5^{\text {th }}$ ed. Paris. 1993; 682.

[10] Géraud MEF. Hematological syndromes of toxic origin in domestic carnivores: Clinical study and literature review. State Doctorate of Veterinary Medicine, National School of Veterinary Medicine, Toulouse, France. 2007; 123.

[11] Goyffon M, Chippaux JP. Terrestrial venomous animals. Encyclopedia of Medicine and Surgery, Paris, France. 1990; 14.

[12] Kassogué A. Kidney complications from snakebite poisoning at SUC HGT from January to December 2004. State Doctorate State Doctorate in Medicine, Faculty of Medicine, Pharmacy and Dentistry and Dentistry-Stomatology. University of Bamako, Mali. 2006; 86. 
[13] Kini RM, Haar NC, Evans HJ. Non-enzymatic inhibitors of coagulation and platelet aggregation from Naja nigricollis venom are cardiotoxins. Biochemical and Biophysical Research Communications. 1988; 150(3): 101216.

[14] Manaoui R. Snake bites in the region of Marrakech Tensift el Haouz. State Doctorate in Medicine, Faculty of Medicine and Pharmacy, Cadi Ayyad University, Marrakech, Morocco. 2007; 73.

[15] Mion G, Larréché S. Cobraic syndrome. Tropical Medicine. 2008; 68: 348-58.

[16] Praag EV. Vitamin D deficiency in rabbits. MediRabbit.com. 2014; 1-7. 